\title{
Fibronectin/integrin interaction induces tyrosine phosphorylation of a 120-kDa protein
}

\author{
Jun-Lin Guan, * Jane E. Trevithick, \\ and Richard O. Hynes \\ Howard Hughes Medical Institute \\ and Center for Cancer Research \\ Department of Biology \\ Massachusetts Institute of Technology \\ Cambridge, Massachusetts 02139
}

\begin{abstract}
We describe a 120-kDa protein (pp120) that is phosphorylated on tyrosine in cells attached to fibronectin-coated surfaces. The protein appears to be located in focal contacts where it codistributes with $\beta_{1}$ integrins. pp120 is distinct from the $\beta_{1}$ subunit of integrins and from vinculin and $\alpha$-actinin. pp120 is rapidly dephosphorylated in cells suspended by trypsinization but becomes rapidly phosphorylated in cells attaching and spreading on fibronectin. Attachment of cells to RGD-containing peptides, polylysine, or concanavalin $A$ is not sufficient to induce phosphorylation of pp120. The 120$k D a$ cell-binding domain of fibronectin can induce some phosphorylation of pp120, but further phosphorylation occurs in the presence also of the heparin-binding domain of fibronectin. Phosphorylation of pp120 precedes, but is correlated with, subsequent cell spreading. Phosphorylation of pp120 can also be triggered by attachment of cells to antiintegrin antibodies, and this requires the cytoplasmic domain of the integrin $\beta_{1}$ subunit. Thus interaction of $\beta_{1}$ integrins with extracellular ligands (fibronectin or antibodies) triggers phosphorylation of an intracellular 120-kDa protein, pp120, that may be involved in the responses of cells to attachment.
\end{abstract}

\section{Introduction}

The interactions of cells with extracellular matrix (ECM) proteins play important roles in a variety of biological processes, including embryonic development, wound healing, and malignant transformation. Both in vivo and in vitro, ECM

\footnotetext{
* Present address: Department of Pathology, New York State College of Veterinary Medicine, Cornell University, Ithaca, NY 14853.
}

proteins markedly influence the growth, migration, and differentiation of higher eukaryotic cells (Hay, 1985; Mosher, 1989; Hynes, 1990). For example, the proliferation of nontransformed fibroblasts in culture is dependent on their adhesion and spreading on a solid surface (Folkman and Moscona, 1978). This property, termed anchorage dependence, is reduced or lost as cells become increasingly transformed (Tucker et al., 1981; Wittelsberger et al., 1981).

Many of the effects of ECM proteins on cellular properties are mediated by their binding to integrins. Integrins are cell surface receptor proteins for a variety of ligands, including ECM proteins such as fibronectins (FNs), laminin, and collagens (Buck and Horwitz, 1987; Hynes, 1987; Ruoslahti and Pierschbacher, 1987; Ruoslahti, 1988). They are heterodimers of noncovalently associated $\alpha$ and $\beta$ subunits. Both subunits of integrins are transmembrane glycoproteins containing a large extracellular domain, a single transmembrane segment, and generally a short cytoplasmic domain. There are at least 11 different integrin $\alpha$ subunits and $7 \beta$ subunits so far identified in mammalian cells (Hemler, 1990). In general, the combination of particular $\alpha$ and $\beta$ subunits determines the ligand specificity of the integrin complex. For example, $\alpha_{5} \beta_{1}$ integrin serves specifically as a FN receptor on many cell types, whereas $\alpha v \beta 3$ acts as a vitronectin receptor (Dejana et al., 1988; Singer et al., 1988). Furthermore, different integrins may recognize distinct sites within the same ECM protein. Thus, $\alpha_{5} \beta_{1}$ interacts with FNs at the central RGDS (arg-gly-asp-ser) sequence, whereas $\alpha_{4} \beta_{1}$ integrin binds to the sequence EILDV in the alternatively spliced $V$ (or III.CS) region (Wayner et al., 1989; Guan and Hynes, 1990; Mould et al., 1990).

In contrast with the great progress made in recent years identifying various integrin complexes and their ligand specificity, little is known about the molecular mechanisms by which integrins transmit information across the plasma membrane. Although they are presumably responsible for triggering the subsequent events leading to alterations in cell growth, migration, 
and differentiation, the immediate intracellular biochemical events induced by integrin/ECM ligand interactions are poorly understood.

Reversible phosphorylation of proteins has long been recognized to regulate various cellular metabolic pathways (Edelman et al., 1987). More recently, protein tyrosine phosphorylation has been implicated in transmitting signals that regulate cell growth and differentiation (Hunter and Cooper, 1985; Hunter, 1987; Ullrich and Schlessinger, 1990). In nontransformed fibroblasts, proteins phosphorylated at tyrosines are concentrated in cell-cell or cell-matrix contacts (Maher et al., 1985). This raises the possibility that protein tyrosine phosphorylation is involved in transducing signals across membranes when integrins bind to ECM proteins and aggregate into focal contacts. Ferrell and Martin (1989) and Golden et al. (1990) have reported tyrosine phosphorylation of several proteins in activated platelets whose phosphorylation relies at least in part on integrin-mediated events. In the present study, we have examined protein tyrosine phosphorylation in fibroblastic cells during attachment and spreading mediated by FNs and/ or integrins.

\section{Results}

\section{Major sites of tyrosine phosphorylation in attached cells}

To study the effects on tyrosine phosphorylation of $\mathrm{FN} /$ integrin interactions, we first examined the distribution of tyrosine phosphorylated proteins in NIH3T3 cells on their adhesion to plasma FN (pFN). Cells were plated on coverslips coated with pFN and allowed to attach and spread for $2 h$ in the absence of serum. They were then fixed, permeabilized, and stained by double-label immunofluorescence using a rabbit serum, 363, against the integrin $\beta_{1}$ subunit and a monoclonal antibody, py20, specific for phosphorylated tyrosines (Glenney et al., 1988). The results are shown in Figure 1. Figure 1B shows the typical distribution of the $\beta_{1}$ subunit in focal contacts of cells plated on FN. Figure $1 \mathrm{~A}$ illustrates the staining pattern of tyrosine phosphorylated proteins detected by py20. Their distribution colocalizes extensively, although not completely, with the integrin $\beta_{1}$ subunit, especially in focal contacts at cell edges (arrows). These results show that tyrosine phosphorylation occurs on proteins in focal contacts in agreement with earlier results (Maher et al., 1985). Focal contacts are likely sites of signal transduction by $\beta_{1}$ integrins on their interaction with the multivalent ligand FN (Burridge et al., 1988).

To identify the tyrosine phosphorylated proteins detected by py20 using immunofluorescence, we next examined the profile of proteins phosphorylated on tyrosines after cell attachment to $\mathrm{pFN}$ by western blotting using the same antibody. Tissue culture dishes were coated with either pFN or poly-L-lysine (PLL), and excess sites on the substrate were then blocked by incubation with bovine serum albumin (BSA). The incubation with BSA effectively blocked attachment of NIH3T3 cells to dishes in the absence of adhesive substrates. NIH3T3 cells were then plated in Dulbecco's Modified Eagle's Medium (DMEM) without serum and incubated for $25 \mathrm{~min}$. After washing, cells were solubilized by RIPA buffer, and nuclei were removed by centrifugation. Protein concentrations of the detergent lysates were then determined, and equal amounts of protein were electrophoresed on polyacrylamide gels and transferred to nitrocellulose membranes (Figure 2B). Western blots were carried out with py20 followed by ${ }^{125} \mathrm{I}-\mathrm{la}$ beled sheep anti-mouse IgG. The autoradiograph of the blotted membrane is shown in Figure 2A. A 120-kDa protein was the major protein detected by py20 and was much more prominent in cells attached to pFN than in those attached to PLL (Figure 2A). Therefore this protein, designated as pp120, is a prime candidate for being a protein detected by the same antibody in the immunofluorescence analysis of cells plated on pFN (Figure 1). Figure $2 \mathrm{C}$ shows the morphology of cells attached to PLL (top) or pFN (bottom) just before lysis in RIPA buffer. At these early times there is little difference in morphology of cells on the two substrates. However, at later times pFN induces spreading of cells, whereas PLL does not (see below).

Similar results were obtained by immunoprecipitation with py20 (data not shown). This precipitation was blocked by inclusion of phosphotyrosine but not phosphoserine or phosphothreonine, confirming the specificity of the antibody. Furthermore, several other antiphosphotyrosine antibodies also detected pp120 as a major band in the lysates of cells plated on FN although the spectrum of other bands varied with different antibodies (data not shown).

The integrin receptors for pFN on NIH3T3 cells include $\alpha_{3} \beta_{1}$ and $\alpha_{5} \beta_{1}$, and the common $\beta_{1}$ subunit contains a site for tyrosine phosphorylation in the cytoplasmic domain (Hirst et al., 1986; Tamkun et al., 1986; Tapley et al., 1989). To determine whether pp120 is the in- 


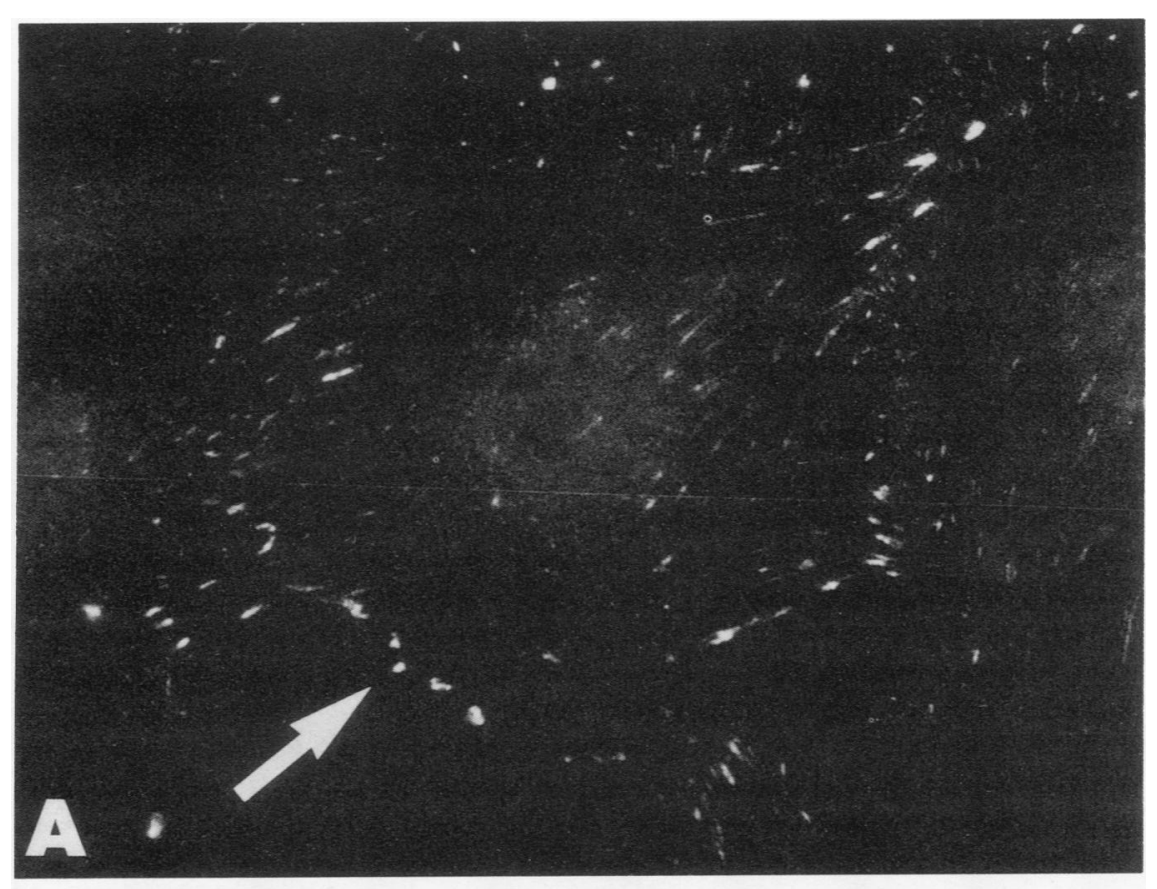

Figure 1. Distribution of tyrosine-phosphorylated proteins in NIH3T3 cells. Cells plated on FN-coated coverslips were processed for immunofluorescence as described in Materials and methods. The monoclonal antibody py20 was used to localize tyrosine phosphorylated proteins (A). The antiserum 363 was used to stain the integrin $\beta_{1}$ subunit in the same cells (B). Note the colocalization of tyrosine phosphorylated proteins with the integrin $\beta_{1}$ subunit in focal contacts at cell edges (arrows).

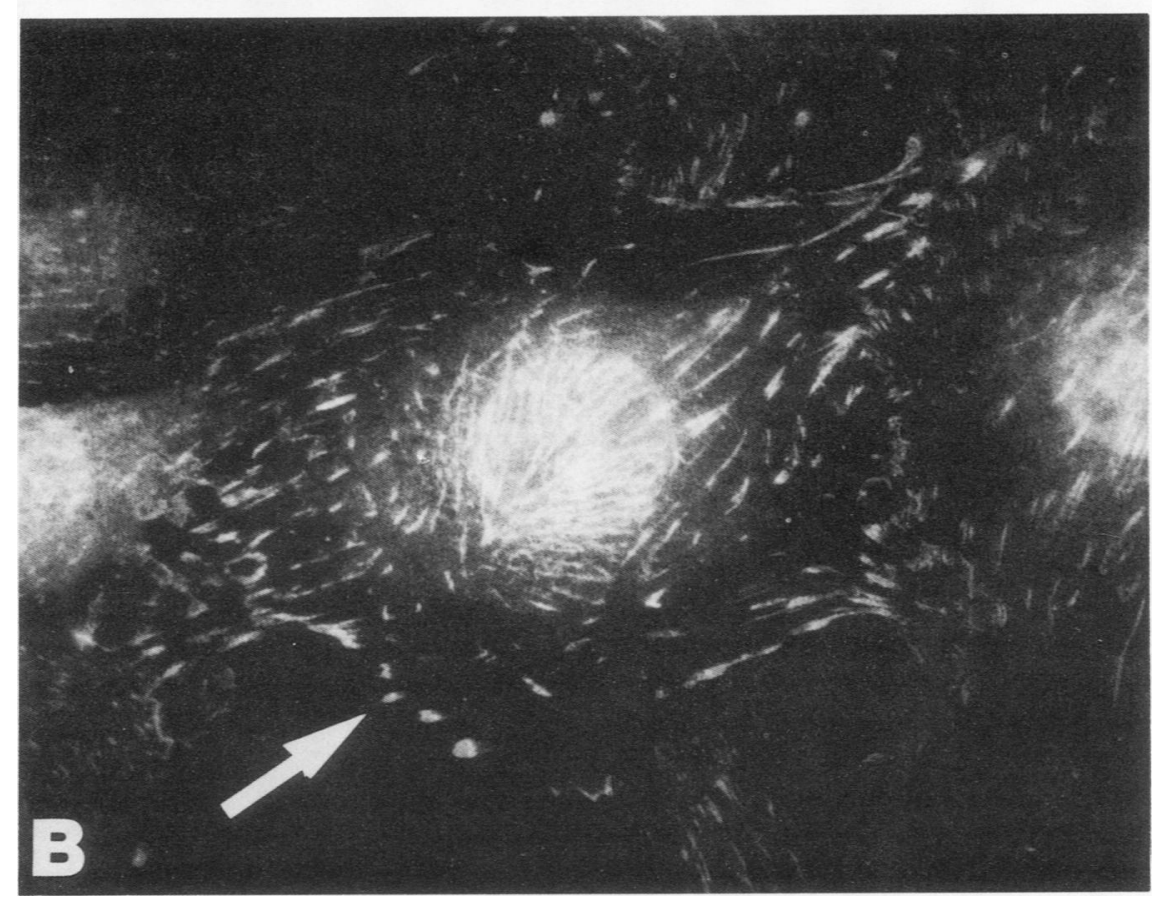

tegrin $\beta_{1}$ subunit itself, we carried out the experiments shown in Figure 3 . Detergent lysates from cells plated on $\mathrm{pFN}$ were incubated with py20-coupled agarose beads at $4{ }^{\circ} \mathrm{C}$ for $1 \mathrm{~h}$. The bound fractions (B) were eluted by boiling in sodium dodecyl sulfate (SDS) sample buffer and loaded on gels along with the total starting material $(T)$ and the unbound fractions (U.B.). Duplicate gels were transferred to nitrocellulose membranes and probed with either py20 (left) or 363 (anti- $\beta_{1}$ serum, right). The asterisk on the left marks pp120, which was largely immunoprecipitated by py20beads in the bound fraction. This bound pro- 

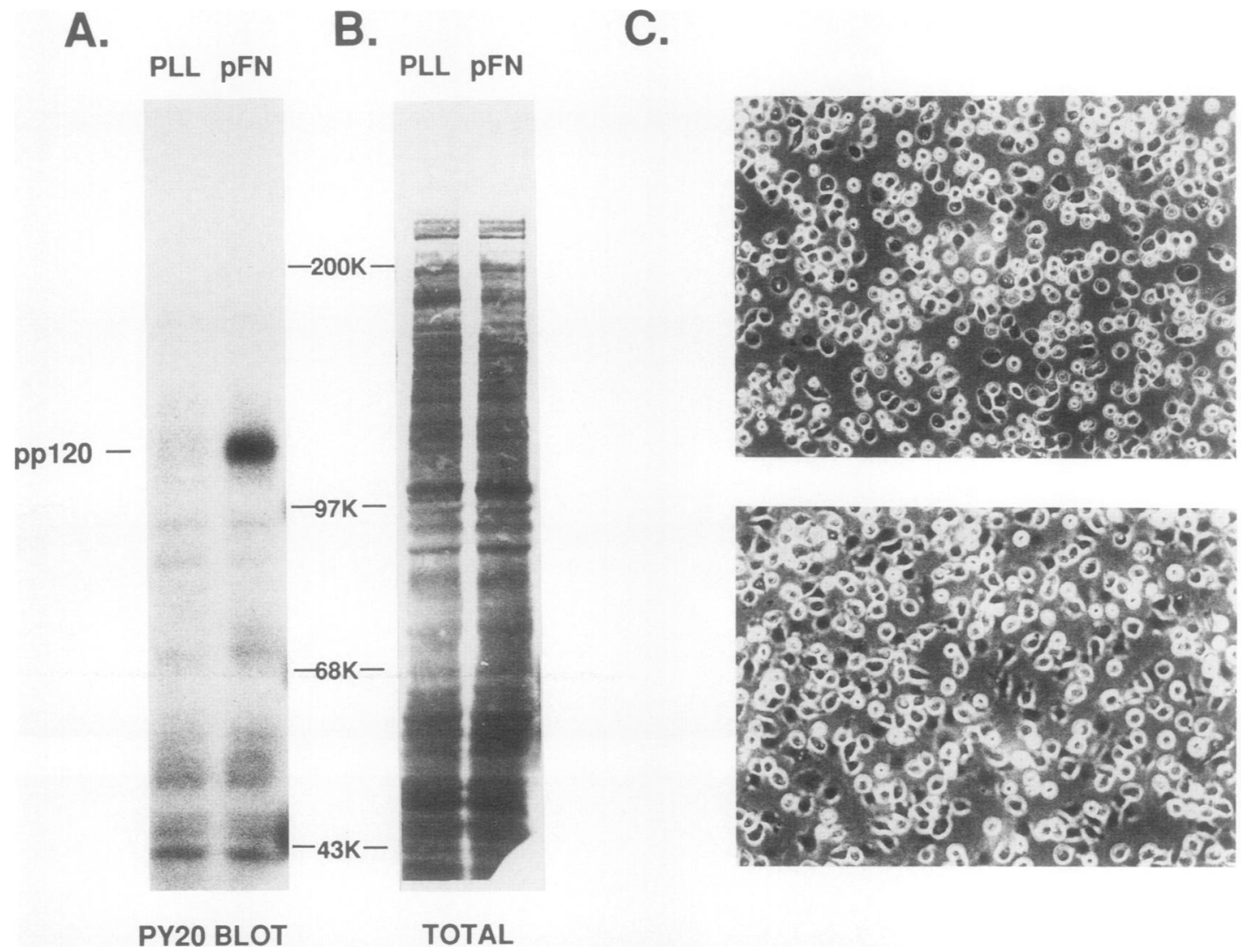

Figure 2. Cell attachment to FN induces tyrosine phosphorylation of a 120-kDa protein. Lysates prepared from cells plated for 25 min on poly-L-lysine (lanes PLL) or plasma FN (lanes pFN) were electrophoresed on polyacrylamide gels and transferred to nitrocellulose membranes. (A) shows autoradiography of the Western immunoblotting with py20 followed by ${ }^{125}$-labeled sheep anti-mouse IgG. (B) shows the total protein in both lanes detected by India ink staining. (C) shows the morphology of cells just before lysis.

tein was not recognized by the anti- $\beta_{1}$ antiserum. In contrast, the $\beta_{1}$ subunit as well as its precursor ( $B$ and pre $B$ marked at the right) was found exclusively in the unbound fraction. Reciprocally, when integrins were precipitated by anti- $\beta_{1}$ antibody (Marcantonio and Hynes, 1988) and the precipitate blotted with py20, no band was detected (data not shown). These distinctions between pp120 and $\beta_{1}$ as well as the apparent differences in mobility on SDSgels indicated that the pp120 protein is not the integrin $\beta_{1}$ subunit. Using similar immunological and electrophoretic criteria, we also ruled out the possibility of pp120 being vinculin or $\alpha$-actinin (data not shown but see below).

The subcellular localization of pp120 was examined in experiments shown in Figure 4. NIH3T3 cells plated on pFN were broken by homogenization in hypotonic buffers. After removing the nuclei by low-speed centrifugation, the supernatants were subjected to ultracentrifugation at $100000 \times g$ for $1 \mathrm{~h}$ at $4^{\circ} \mathrm{C}$ to separate the membranes (pellet) from the cytoplasmic (soluble) fractions. These two fractions were adjusted to equal volumes, and aliquots were electrophoresed, transferred, and blotted with various antibodies. Figure 4, left, shows that pp120 distributes approximately equally in both membrane (P) and cytosol (S) fractions. Vinculin was similarly distributed in both fractions with more in the cytosol but does not comigrate with pp120 (middle), whereas the integrin $\beta_{1}$ subunit was fractionated exclusively into the membrane fraction as expected (right). Thus, pp120 does not appear to be identical with any of the known major constituents of focal contacts and does not behave as an integral membrane protein. 
Figure 3. $\mathrm{pp} 120$ is not the integrin $\beta_{1}$ subunit. Lysates from cells plated on pFN were immunoprecipitated using py20-coupled agarose beads. The bound fractions (B) were eluted by boiling in SDS sample buffer and loaded on gels along with aliquots of the total starting material $(T)$ and the unbound fractions (U.B.). Duplicate gels were transferred to nitrocellulose membranes and probed with either py20 (left) or 363 (anti- $\beta_{1}$ serum, right). The asterisk on the left marks pp120.

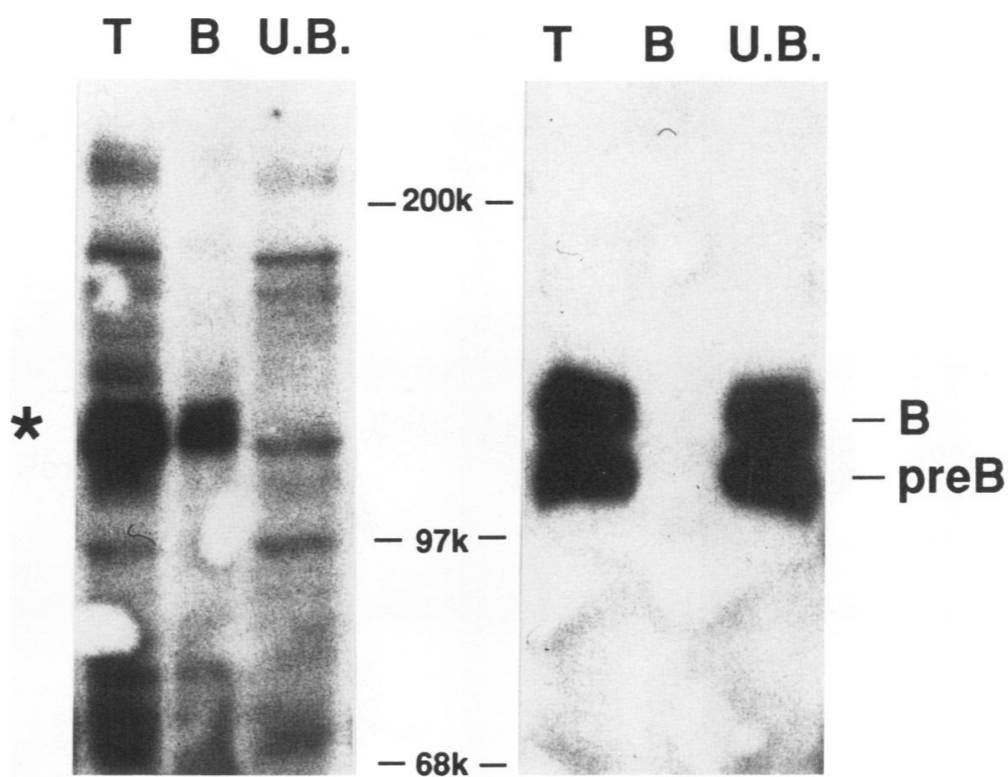

PY20

\section{Involvement of specific segments of fibronectins}

To determine the particular segments of FN that are involved in inducing pp120 phosphorylation, NIH3T3 cells were plated on a variety of adhesive substrates for $1 \mathrm{~h}$ and pp120 phosphorylation was then quantitated by western blotting using py20 as described above. As shown in Figure 5A, pFN (column C) induced significant levels of pp120 phosphorylation above the background level observed on PLL (column B). Another nonspecific cell adhesive substrate, concanavalin $A$ (column $D$ ), failed to induce pp120 phosphorylation. Furthermore, neither collagen type IV (column E) nor laminin (column F) was able to induce the change, although these cells contain an integrin receptor reported to recognize them $\left(\alpha_{3} \beta_{1}\right)$. Columns G-J show results from cells plated on several different $\mathrm{FN}$ fragments, including an RGD-containing pep-tide called peptite-2000 (column G); the 120-kDa chymotryptic fragment, which contains the central cell-binding domain but lacks the heparin-binding domain (column $\mathrm{H}$ ); and two recombinant $\mathrm{FN}$ fragments consisting of type III repeats $1117-11115$ comprising both the cell- and heparin-binding domains of FN, with (7-15.BAV, column J) or without (7-15.0, column I) the alternatively spliced regions (generous gift of Paul Johnson and John
Peters, MIT, Cambridge, MA). These results showed that the recombinant FN fragments containing both the central cell-binding domain and the carboxyl heparin-binding domain were fully functional, whereas the 120-kDa fragment used at the same concentration was active but at a significantly reduced level. Interestingly, the RGD peptide peptite-2000 did not induce any significant level of pp120 phosphorylation at doses from 0.1 to $100 \mu \mathrm{g} / \mathrm{ml}$ and for various lengths of time (see also below). We also noted that the ability of various substrates to induce pp120 phosphorylation seemed to be correlated with their ability to induce extensive cell spreading (see Figure 5, panels B-J). There was no obvious effect of the three alternatively spliced segments of FN either on spreading of NIH3T3 cells or on phosphorylation of pp120 (compare $\mathrm{I}$ and $\mathrm{J}$ ).

To explore further the possible links between cell spreading and pp120 phosphorylation, time course experiments were carried out for cells plated on pFN and peptite-2000 as shown in Figure 6. Cells were photographed and lysed at various times after plating as indicated. Equal amounts of protein were then analyzed by western blotting with py20 as described above. The top panel shows that pp120 phosphorylation (marked *) is significant in attached growing cells $(G)$, falls to low levels on trypsinization of 


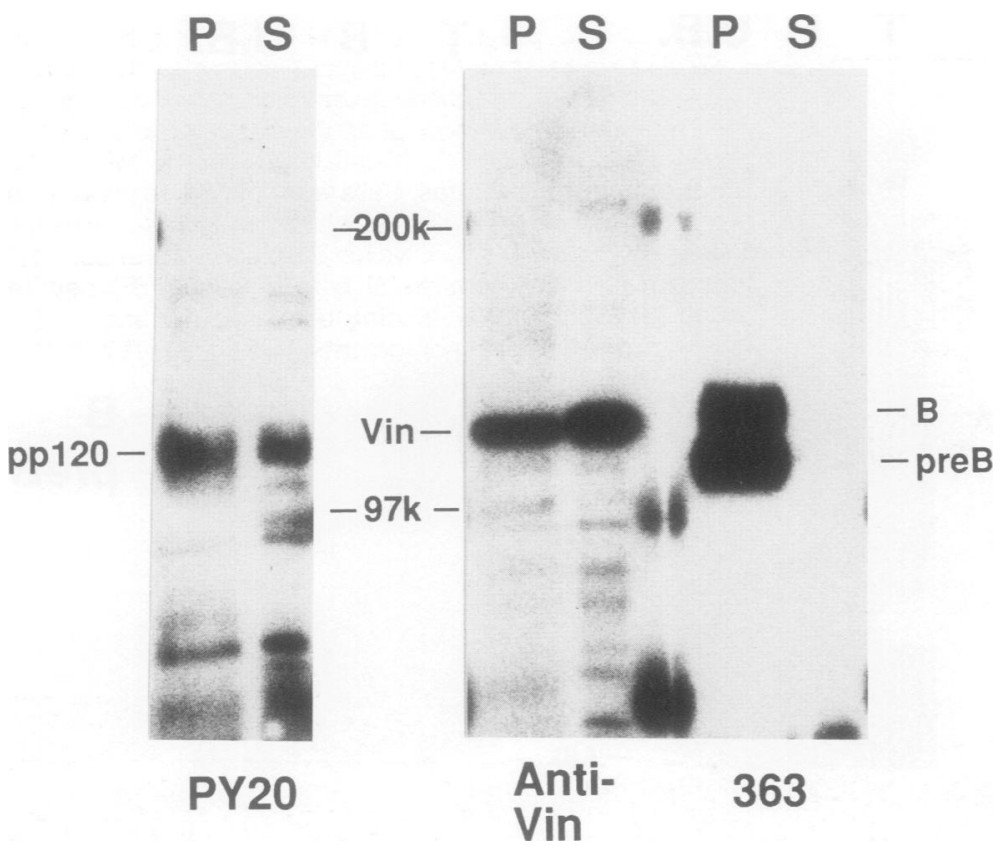

Figure 4. pp120 exists in both cytosolic and membrane fractions. Cells plated on pFN were homogenized in hypotonic buffers and fractionated as described in $\mathrm{Ma}$ terials and methods. The membrane (lanes P) and the cytosol (lanes S) fractions were adjusted to the same volumes and aliquots were electrophoresed, transferred, and blotted with py20 (left), anti-vinculin (middle), or 363 anti $\beta_{1}$ integrin serum (right). The location of pp120, vinculin, and integrin $\beta_{1}$ and its precursor are marked at the sides. the cells $\left(0^{\prime}\right)$, and again reaches maximal levels by the earliest time point $(10 \mathrm{~min})$ after cells are plated on pFN. The phosphorylation of pp120 in cells plated on peptite-2000 remained low throughout the time course; similar results were obtained for cells plated on PLL in time course experiments (not shown). Figure 6 also shows that, by $10 \mathrm{~min}$ after plating, cells attached to both pFN and peptite-2000 without spreading or apparent distinctions in morphology on these two substrates. This indicated that $\mathrm{pp} 120$ phosphorylation was not a consequence of cell spreading. At $3 \mathrm{~h}$ after plating, however, cells were fully spread on pFN but remained round on peptite-2000 suggesting a possible link between pp120 phosphorylation and later cell spreading.

\section{Involvement of integrin $\beta_{1}$ subunit}

The integrin $\beta_{1}$ subunit is the common subunit of cell surface integrin receptors for $\mathrm{pFN}$. To investigate its role in mediating pp120 phosphorylation, we used NIH3T3 cell lines stably expressing the heterologous chicken integrin $\beta_{1}$ subunit or its mutated forms (Solowska et al., 1989; Marcantonio et al., 1990). Cells were plated on dishes coated with the monoclonal antibody CSAT that interacts with the ligandbinding site of the integrin $\beta_{1}$ subunit and is chicken-specific. Cells plated on PLL or pFN were used as negative and positive controls.
Cell lysates were analyzed by western blotting with py20 as described, and an autoradiograph is shown in Figure 7 with pp120 marked by an asterisk at the left. All cells showed phosphorylation of pp120 when attached to pFN via endogenous integrins (lanes F). However, when the effects of attachment via the transfected chicken integrins were examined by attachment to CSAT antibody (lanes $\mathrm{C}$ ), marked differences were observed among the different mutated forms. The wild type (WT) chicken integrin $\beta_{1}$ subunit was able to induce partial pp120 phosphorylation on cell attachment to CSAT. However, the deletion mutants $\Delta 1, \Delta 2, \Delta 4$, and $\Delta 5$ lacking various lengths of the cytoplasmic domain failed to induce the same change. A mutation changing tyr788 to phe (YF) did not abolish the ability of the chicken $\beta_{1}$ to induce pp120 phosphorylation on cells plated on CSAT. These results demonstrated that the integrin $\beta_{1}$ subunit is at least partially responsible for mediating pFN-induced pp120 tyrosine phosphorylation and that its cytoplasmic interactions are critical for this activity. Furthermore, the hydroxyl group of tyr788 seems not to be important (YF), whereas the last four amino acids missing in mutant $\Delta 5$ might be involved in the cytoplasmic interactions of integrin $\beta_{1}$ necessary for pp120 phosphorylation. Figure 7B shows the adhesion kinetics of transfected 3T3 cells 
A.

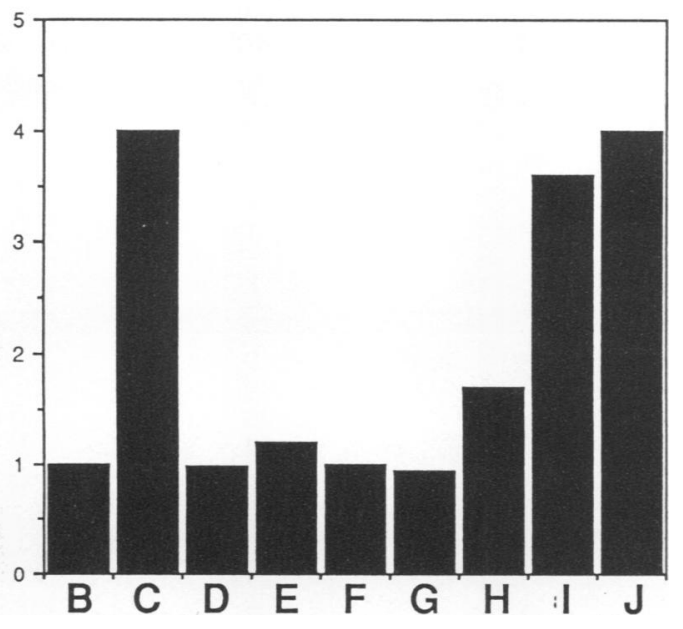

Figure 5. Phosporylation of pp120 and cell spreading on different substrates. (A) phosphorylation of pp120 quantitated by computing densitometer as described in Materials and methods. The level of phosphorylation on poly $L$ lysine was set as 1 (column B). (B-J) Morphology of cells plated on the various substrates. Cells were plated on various adhesive substrates for $1 \mathrm{~h}$ and photographed after washing. The substrates are poly $L$ lysine (B), plasma fibronectin (C), concanavalin $A(D)$, laminin $(E)$, type IV collagen $(F)$, peptite$2000(G), 120-k D a$ cell-binding domain of fibronectin (H), recombinant fibronectin fragments 7-15.0 (I), and 7-15.BAV (J).
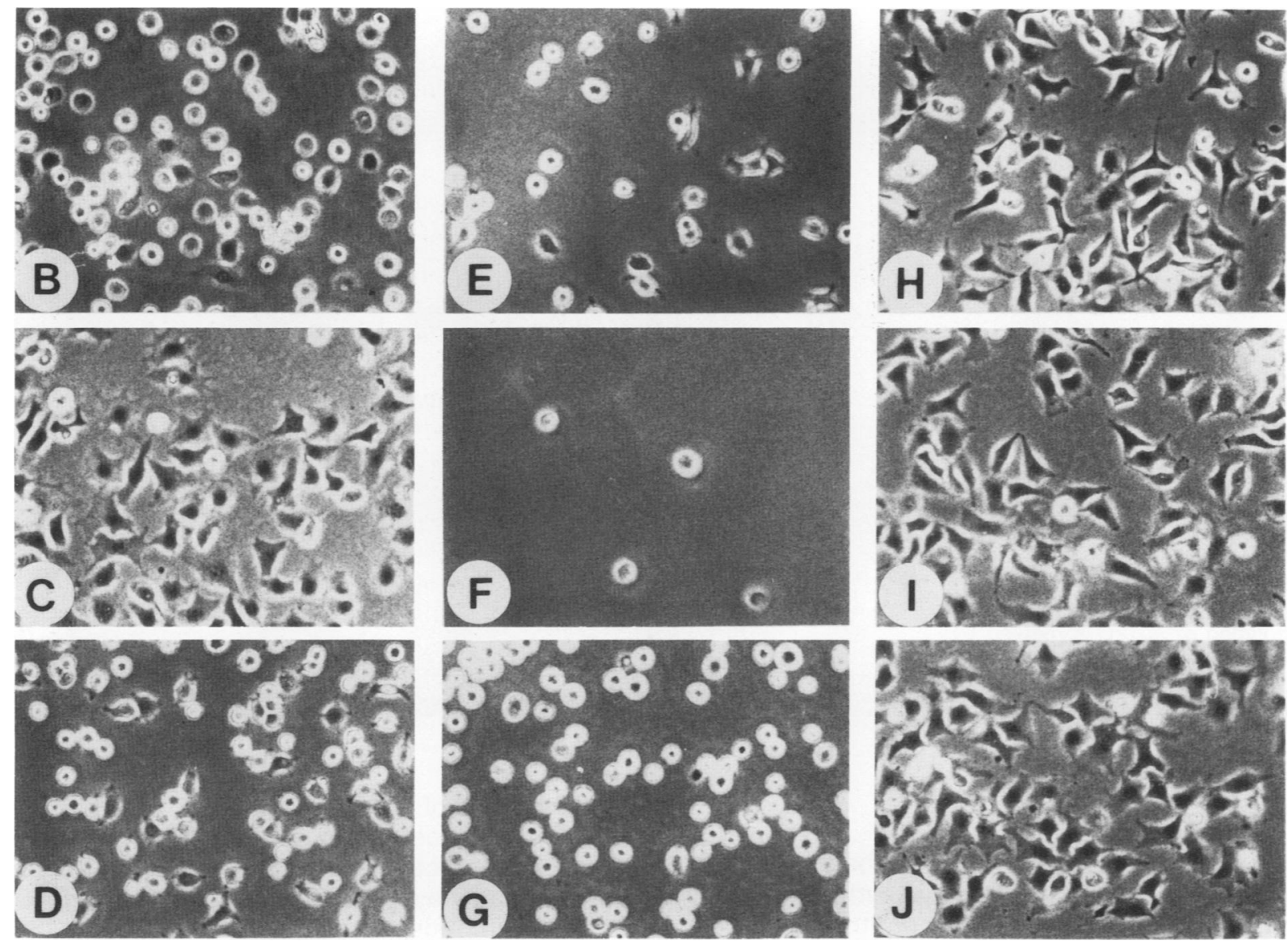

on CSAT monoclonal antibody. At $30 \mathrm{~min}$ after plating, all cells attached to the antibody substrates as well as to PLL or pFN. However, we noticed that $\Delta 1, \Delta 2, \Delta 4$, and $\Delta 5$ transfected cells appeared to be rounder than WT and YF transfected cells. Furthermore, these cells detached from the substrates by $3 \mathrm{~h}$, whereas cells transfected with WT and YF remained attached. These results suggested a correlation between pp120 phosphorylation and stable attachment to substrates in integrin-mediated adhesion. 


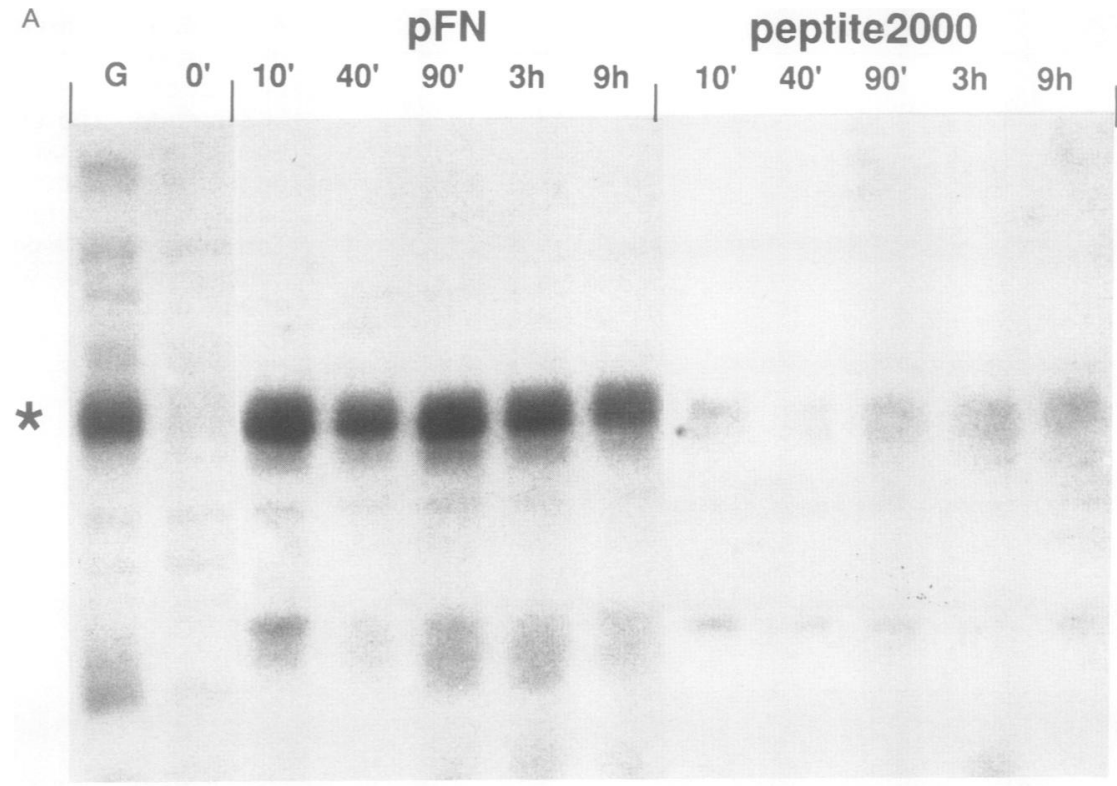

Figure 6. Time course of induction of pp120 phosphorylation. (A) shows western blotting of detergent lysates prepared from cells after plating on $\mathrm{pFN}$ and peptite-2000 for various times as indicated. Lane $\mathrm{G}$ and $0^{\prime}$ are cell lysates from, respectively, growing monolayer and suspended 3T 3 cells just before plating. The position of pp120 is marked by an asterisk at the left. (B) shows morphology of cells just before lysis at $10^{\prime}$ or $3 \mathrm{~h}$ after plating.

B
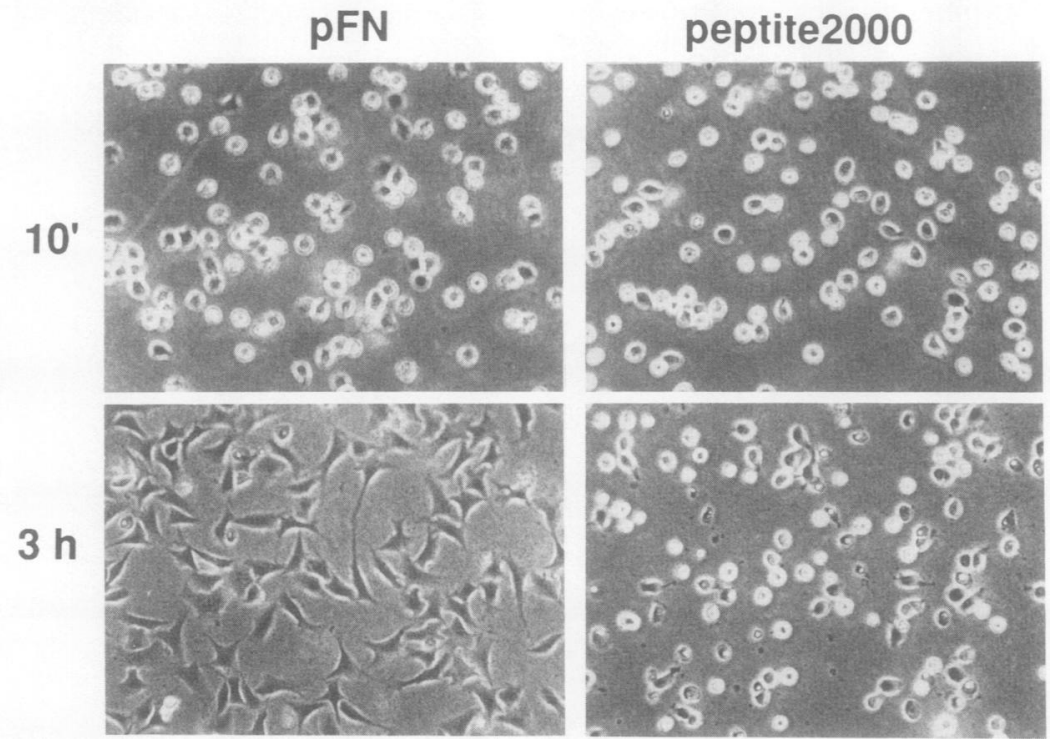

\section{Discussion}

In multicellular organisms, the behavior of individual cells such as their growth, differentiation, and migration is tightly controlled by their extracellular environments. Two major classes of controlling components are diffusible peptide growth factors and insoluble extracellular matrix proteins. These two classes of molecules influence cellular behavior both independently and cooperatively (Ruoslahti and Yamaguchi, 1991; Yayon et al., 1991). Rapid progress has been made in recent years elucidating the molecular mechanisms of the soluble growth factors. They bind to their cell surface receptors, which results in the activation of several second messenger pathways. These pathways often involve a series of phosphorylation events that are dependent on the activation of protein kinases. The activation of the second messenger pathways in turn triggers a series of downstream events that alter gene expression and cellular structures to affect cell properties (Sibley et al., 1987; Yarden and Ullrich, 1988; Williams, 1989). In contrast, little is known about the molecular mechanisms by which insoluble matrix proteins 


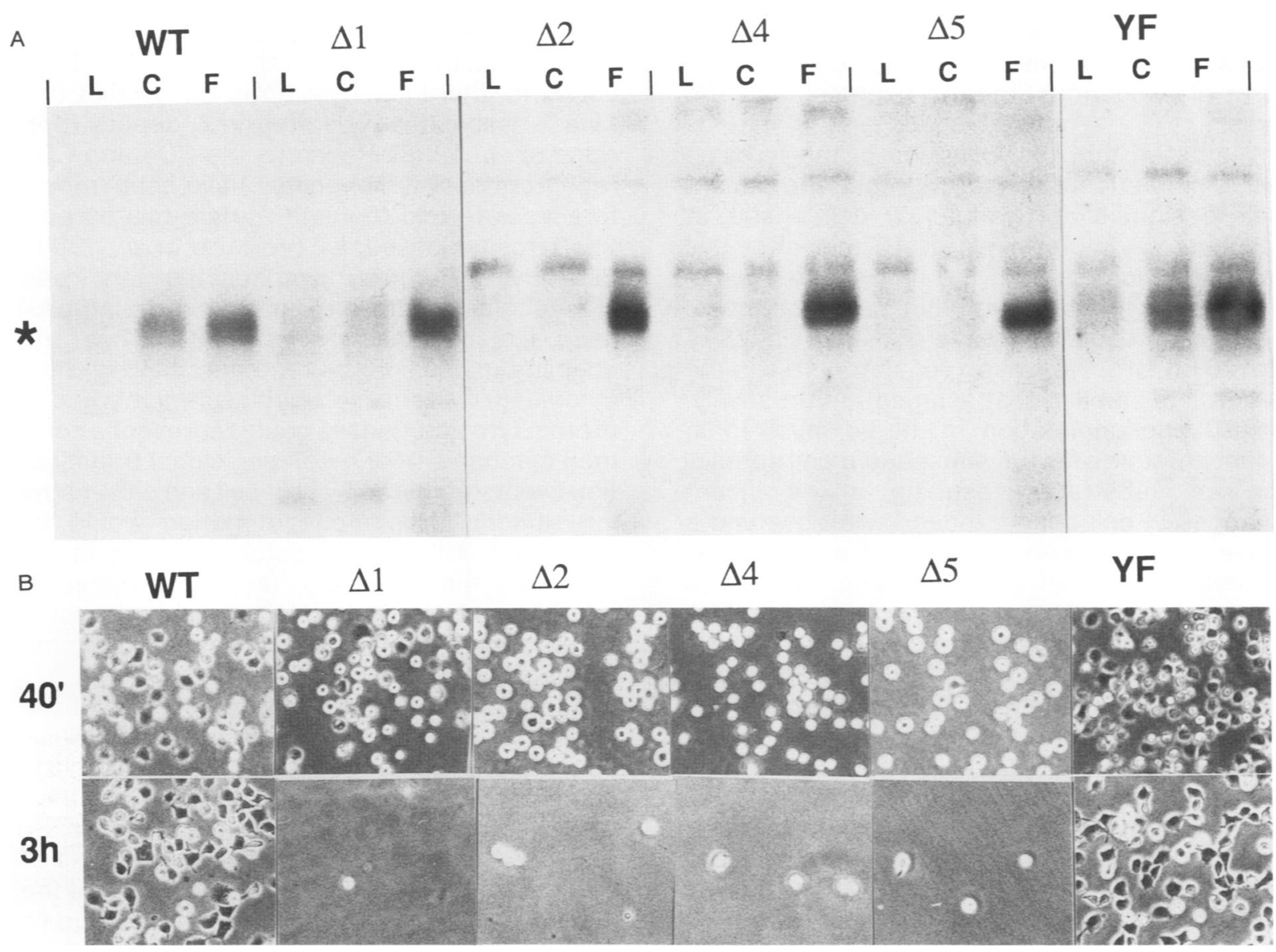

Figure 7. Integrin $\beta_{1}$ subunit is involved in inducing pp120 phosphorylation. NIH3T3 cells stably expressing the heterologous chicken integrin $\beta$, subunit (WT) or various cytoplasmic mutations ( $\Delta 1$ lacking $40, \Delta 2$ lacking $37, \Delta 4$ lacking 13, $\Delta 5$ lacking 4 amino acids, and YF in which tyr 788 is changed to phe) were plated on PLL (lanes L), CSAT antibody (lanes C), or pFN (lanes F). Lysates were prepared and analyzed by western blotting as described in the Materials and methods (A). The position of pp120 is marked by an asterisk at the left. Cells remaining attached to CSAT antibody at $40 \mathrm{~min}$ or $3 \mathrm{~h}$ were photographed and are shown in (B).

transduce signals across the plasma membrane. Recent identification of integrins as the cell surface receptors for many extracellular matrix proteins and molecular cloning of the genes for integrins has opened the way to investigate these questions at the molecular level.

In this report, we showed that attachment of fibroblasts to FNs induced tyrosine phosphorylation of a protein, pp120, in the absence of any added soluble growth factors. This induction was rapid and preceded cell spreading. The central regions of $\mathrm{FN}$ molecules, including both the cell binding domain and high-affinity heparin binding domain, appeared to be sufficient to induce the response, whereas attachment of cells to RGD-containing peptides or to several other adhesive ligands was insufficient. We also showed that phosphorylation of pp120 can be mediated by integrin receptors on the cell surface and that the cytoplasmic domain of the integrin $\beta_{1}$ subunit is essential for this. These results implicate protein tyrosine kinases in signal transduction by integrin receptors for FN.

The possibility that the FN or CSAT preparations contain soluble growth factors that are responsible for the induction of phosphorylation of pp120 is rendered unlikely by several observations. The same results are obtained with plasma $\mathrm{FN}$ and with several recombinant $\mathrm{FN}$ fragments produced in Chinese hamster ovary (CHO) cells grown in serum-free medium (Figure 5). Furthermore, phosphorylation of pp120 is also induced by CSAT antibody in a fashion dependent on the form of chicken integrin $\beta_{1}$ subunit expressed by the cells (Figure 7). If the effect of the CSAT preparation was due to 
contaminating growth factors, there is no obvious reason for the dependence on the exact form of exogenous integrin expressed by the cells.

We noted that the induction of the tyrosine phosphorylation of pp120 is rapid and occurs before significant changes in cell shape. It reaches maximum levels at $10 \mathrm{~min}$ after cell plating, which is about the time it takes for fibroblasts to attach to FN-coated surfaces. Thus, it is possible that the phosphorylation of pp120 on tyrosine plays a regulatory role in the process of stable cell attachment. Alternatively, pp120 phosphorylation might be involved in events required for the subsequent cell spreading on substrates resulting in significant changes in cell shape. Indeed, we observed a correlation between induction of pp120 phosphorylation and of cell spreading by various substrates (Figure 5). Interestingly, the 120-kDa chymotryptic fragment of pFN induces only intermediate levels of pp120 phosphorylation while apparently supporting cell spreading. Previous experiments by LeBaron et al. (1988) and Woods et al. (1988) have shown that the cell-binding domain alone does not cause full cell spreading in the sense that focal contacts are not observed in fibroblasts plated on it. The heparin-binding domain in combination with the cell-binding domain is necessary to induce full cell spreading and focal contact formation. In agreement with this, two recombinant FN segments, 7-15.0 and 7-15.BAV, containing both the cell-binding domain and the heparin-binding domain induced high levels of pp120 phosphorylation (Figure 5).

The extent of cell spreading has previously been linked to the growth control of nontransformed cells (Folkman and Moscona, 1978). Besides the obvious possibility that cell spreading controls cell proliferation directly through its influence on the cytoskeleton, it is possible that both parameters are dependent on a third factor related in some way to substrate, as the authors pointed out. The phosphorylation of pp120 might be a candidate for such a third factor that regulates both cell spreading and proliferation. Therefore, pp120 phosphorylation could influence cellular behavior either directly or through its effects on cell spreading. The resolution of these possibilities requires further studies using reagents specific for pp120.

Our results also point to a critical role of the cytoplasmic domain of integrin $\beta_{1}$ in mediating phosphorylation of pp120. This raises the question as to whether this domain interacts with a protein-tyrosine kinase. Although the v-src gene product can be localized with integrin $\beta_{1}$ in focal contacts, there is as yet no evidence that this kinase associates with integrin $\beta_{1}$ directly (Burridge et al., 1988). Recently, the CD4 and CD8 receptors on $T$ lymphocytes have been shown to associate and regulate the src-related protein-tyrosine kinase, Ick (Veillette et al., 1988). Similarly, IgM on B lymphocytes has been shown to associate with another src-related kinase, Iyn (Yamanashi et al., 1991). Thus, the coupling of cell surface receptors having short cytoplasmic domains with submembranous protein tyrosine kinases could represent a common mechanism for mediating signal transduction events triggered by cell-cell and cell-matrix interactions. This mode of action would be analogous with that of soluble growth factor receptors that generally have large cytoplasmic domains with intrinsic protein tyrosine kinase activities regulated by extracellular ligand binding.

Alternatively, the cytoplasmic domain of the integrin $\beta_{1}$ subunit may mediate intracellular phosphorylation events by associating with the putative substrates and bringing them to their physiological kinases on cell binding to FNs. Focal contacts in fibroblasts are likely sites of such actions and have been proposed to be the location at which ECM transduces signals across plasma membranes (Burridge et al., 1988). The cytoplasmic domain of integrin $\beta_{1}$ has been shown to bind to talin and $\alpha$-actinin and recruit them to focal contacts when cells were plated on FN (Horwitz et al., 1986; Dejana et al., 1988; Singer et al., 1988; Tapley et al., 1989; Otey et al., 1990). In this respect, it is worth noting that the platelet integrin GPIIbllla (integrin $\alpha_{11 \mathrm{~b}} \beta_{3}$ ) also induces tyrosine phosphorylation of several intracellular proteins concomitant with its induction of platelet aggregation (Ferrell and Martin, 1989; Golden et al., 1990). Therefore, aggregation of cell surface receptors might be a general phenomenon required for integrinmediated signal transductions. Aggregation of receptors might be required for several reasons. First, the affinity of interactions between the integrin cytoplasmic domain and the putative kinases or substrates might be low so that aggregation of multiple receptors is necessary to produce high avidity interactions to bring kinases and substrates together. Second, multiple proteins might be involved in a series of events that lead to activation of a kinase to phosphorylate pp120. Receptor aggregation may be necessary to induce interactions among 
multiple proteins. Consistent with this idea is the requirement for several domains of FN for induction of full phosphorylation of pp120. The role of multiple receptors in assuring stable cellcell interactions was demonstrated previously for T lymphocytes with their target cells (Springer, 1990). Last, aggregation of integrin receptors with their interacting components might be necessary to generate regions of plasma membrane that segregate phosphorylated pp120 from cellular protein tyrosine phosphatases. This is in agreement with the sustained phosphorylation of pp120 in growing cells and its rapid dephosphorylation on cell detachment from substrates by a number of different methods (Fig. 6 and our unpublished observation). Finally, it should be pointed out that the above three possibilities were not mutually exclusive and could all be necessary for pp120 phosphorylation induced by $\mathrm{FN} /$ integrin interactions. Testing of these hypotheses requires identification of pp120 and preparation of specific reagents to it.

Although the identity of pp120 is unknown at present, our experiments suggest that it is a major tyrosine-phosphorylated protein in nontransformed fibroblasts and is possibly localized in the inner membrane and focal contacts in cells plated on FN. Maher and Pasquale (1988) have reported a 120-kDa tyrosine-phosphorylated protein in many embryonic tissues, and Pasquale et al. (1988) have described a tyrosinephosphorylated protein of similar molecular weight in Balbc3T3 cells and showed that tyrosine phosphorylation of the protein was stimulated by a variety of soluble growth factors. This protein was also localized to focal contacts as detected by polyclonal anti-phosphotyrosine serum. If indeed this phosphoprotein is identical with pp120 described in this report, that would suggest a role for pp120 in integrating signals generated by both soluble growth factors and insoluble ECM proteins. Others have reported a protein of similar size as a substrate for the insulin receptor protein tyrosine kinase (ReesJones and Taylor, 1985; Sadoul et al., 1985). Cooperation between soluble growth factors and ECM exists in many biological systems, and study of regulation of pp120 phosphorylation may allow examination of the molecular mechanisms underlying this cooperativity. In particular, it could shed light on our understanding of growth regulation of both normal and malignant cells. For example, the following hypothesis could be offered to explain the anchorage-independent growth of transformed cells. In nor- mal cells stimulated by high levels of growth factors or in transformed cells where cytoplasmic kinases are constantly turned on, critical substrates including pp120 might be highly phosphorylated independent of cell attachment to matrix. Indeed Linder and Burr (1988) and Reynolds et al. (1989) have reported elevated phosphorylation of several proteins of around $120 \mathrm{kDa}$ correlating with oncogenic transformation in chicken embryo fibroblasts infected with viruses encoding membrane-associated pp60 ${ }^{\text {src }}$, a known tyrosine protein kinase. These phosphoproteins could be related to the pp120 described here. Preliminary results using antibodies provided by Dr. J.T. Parsons (Kanner et al., 1990) do suggest some cross-reactivity (J.-L. Guan, unpublished data). Thus one could postulate that elevated levels of phosphorylation of pp120 could occur constitutively in transformed cells but that normal cells require either high levels of growth factors or cooperation between growth factors and matrix adhesion (anchorage dependence) to achieve sufficient levels of phosphorylation. Alternatively, adequate phosphorylation of pp120 and other substrates in normal cells might require clustering of kinases and their substrates together and perhaps also away from cellular phosphatases. These processes might be controlled by ECM molecules through their integrin receptors. These models are testable and will be examined.

In conclusion, we have demonstrated that integrin/FN interactions can regulate tyrosine phosphorylation in the absence of any added soluble growth factors. This may provide a mechanism by which integrins convey information across membranes, which is responsible for triggering the subsequent events necessary for ECM to influence cellular behavior. Identification of pp120 will allow us to study the biological consequences of its phosphorylation and its role in integrin-mediated signal transduction. Use of cytoplasmic domain mutants of the integrin $\beta_{1}$ subunit in transfected cells will allow us to dissect in detail the mode of regulation of pp120 phosphorylation and its relationships with other integrin $\beta_{1}$-mediated events in focal contacts.

\section{Materials and methods}

\section{Cells and reagents}

NIH3T3 cells were maintained in DMEM plus $10 \%$ calf serum (CS, GIBCO Laboratories, Grand Island, NY). NIH3T3 cells expressing the chicken integrin $\beta_{1}$ subunit and its various mutations were described previously (Marcantonio et al., 1990; Solowska et al., 1989), and they were maintained in 


\section{J.-L. Guan et al.}

DMEM plus $10 \%$ CS and $0.5 \mathrm{mg} / \mathrm{ml} \mathrm{G418}$ (GIBCO Laboratories). The mutations are $\Delta 1$ lacking $40, \Delta 2$ lacking 37 , $\Delta 4$ lacking $13, \Delta 5$ lacking 4 amino acids from the carboxyl terminus, and YF in which tyr 788 is changed to phe. Rat pFN, peptite-2000, 120-kDa chymotryptic fragment of human pFN, and mouse laminin were purchased from Telios (San Diego, CA). PLL and concanavalin A were obtained from Sigma (St. Louis, MO) and type IV collagen was purchased from Collaborative Research (Lexington, MA). Recombinant $F N$ fragments 7-15.0 and 7-15.BAV produced in $\mathrm{CHO}$ cells grown in serum-free medium and purified by affinity chromatography on columns of a monoclonal antibody specific for rat fibronectins were generous gifts of Drs. Paul Johnson and John Peters of our Laboratory. Monoclonal antibody py20 (Glenney et al., 1988) was purchased from ICN (Costa Mesa, CA) and also kindly provided by Dr. Glenney, Jr. (University of Kentucky). CSAT monoclonal antibody was prepared by affinity chromatography on protein A Sepharose from hybridomas (Neff et al., 1982) kindly provided by Dr. Clayton Buck (Wistar Institute, Philadelphia, PA). Polyclonal antiserum 363 was described previously (Marcantonio and Hynes, 1988) and monoclonal antibody against vinculin was purchased from Sigma.

\section{Immunofluorescence}

Cells were plated in DMEM without serum for $2 \mathrm{~h}$ on coverslips previously coated with rat $\mathrm{pFN}(10 \mu \mathrm{g} / \mathrm{ml})$. They were rinsed twice in phosphate-buffered saline (PBS) and fixed for $15 \mathrm{~min}$ in a freshly prepared $4 \%$ solution of paraformaldehyde (Fluka Chemical Co., Buchs, Switzerland) in PBS, rinsed, and permeabilized with $0.5 \%$ NP40 in PBS for 15 min. Cells were stained with primary antibody in $10 \%$ normal goat serum in PBS for $30 \mathrm{~min}$ at $37^{\circ} \mathrm{C}$. After three washes with PBS, the secondary antibody mixture (rhodamine-conjugated goat anti-rabbit lgG and fluorescein-conjugated goat anti-mouse lgG in 10\% normal goat serum in PBS; Organon Teknika-Cappel, Malvern, PA) was added and incubated for $30 \mathrm{~min}$ at $37^{\circ} \mathrm{C}$. After three washes, coverslips were mounted in Gelvatol and examined using an Axiophot microscope (Carl Zeiss, Inc., Thornwood, NY) and photographed (Tri-X film; Eastman Kodak Co., Rochester, NY).

\section{Preparation of detergent lysates from cells plated on various substrates}

Tissue culture plates were coated overnight with various substrates at $4^{\circ} \mathrm{C}$, washed twice with PBS, and then incubated with $2 \mathrm{mg} / \mathrm{ml}$ heat-inactivated $\left(1 \mathrm{~h}\right.$ at $\left.70^{\circ} \mathrm{C}\right) \mathrm{BSA}$ in PBS for $2 \mathrm{~h}$ at $37^{\circ} \mathrm{C}$. Cells were harvested by brief trypsinization and then washed twice with PBS containing $0.5 \mathrm{mg} /$ $\mathrm{ml}$ soybean trypsin inhibitor (Sigma). The cells were resuspended in DMEM without serum and added to coated plates at $10^{6} / \mathrm{ml}$ ( $1 \mathrm{ml}$ for $35-\mathrm{mm}$ plate or $2.5 \mathrm{ml}$ for $60-\mathrm{mm}$ plate). After various times of incubation at $37^{\circ} \mathrm{C}$, cells were washed twice with cold PBS and lysed in RIPA buffer $(150 \mathrm{mM} \mathrm{NaCl}$, $50 \mathrm{mM}$ tris(hydroxymethyl)aminomethane [Tris], pH7.5, 1\% Triton X-100, $1 \%$ deoxycholate, $0.1 \%$ SDS, and 2 mM EDTA) containing a cocktail of protease and phosphatase inhibitors (2 $\mathrm{mM}$ phenylmethylsulfonyl fluoride [PMSF], $0.2 \mathrm{TIU} / \mathrm{ml}$ aprotinin, $1 \mu \mathrm{g} / \mathrm{ml}$ leupeptin, $0.5 \mathrm{mM}$ vanadate, $50 \mathrm{mM} \mathrm{NaF}$, and $30 \mathrm{mM}$ sodium phosphate). The cell lysates were centrifuged for $10 \mathrm{~min}$ at $4^{\circ} \mathrm{C}$ in a microfuge to remove nuclei. The protein concentrations in the supernatants were determined using BioRad Protein Assay (Richmond, CA). In some experiments, adherent cells were photographed just before lysis using a Nikon inverted phase-contrast microscope.

\section{Western immunoblotting}

Equal amounts of protein lysates prepared from cells on various substrates were electrophoresed on $7 \%$ SDS-polyacrylamide gel electrophoresis by the method of Laemmli (1970). Proteins were electrophoretically transferred to nitrocellulose filters (Schleicher and Schuell, Inc., Keene, NH) for $2 \mathrm{~h}$ at $250 \mathrm{~mA}$ (Towbin et al., 1979). Filters were stained with India ink to confirm the presence of equal amounts of cellular proteins in all lanes. They were then blocked with blocking buffer ( $5 \%$ BSA in TBS; $150 \mathrm{mM} \mathrm{NaCl}, 50 \mathrm{mM}$ Tris, $\mathrm{pH} 7.4$ ) for $2 \mathrm{~h}$ and incubated with py20 at $1 \mu \mathrm{g} / \mathrm{ml}$ in blocking buffer overnight. After washing with TBS containing $0.5 \%$ Tween-20, the filters were incubated for $2 \mathrm{~h}$ with ${ }^{125}$-labeled sheep anti-mouse IgG $(0.15 \mu \mathrm{Ci} / \mathrm{ml}$; Amersham Corp., Arlington Heights, IL). The filters were then washed, dried, and exposed to XAR-5 film (Eastman Kodak Co.) with an enhancing screen. Quantitation of the autoradiographs was carried out by computing densitometer (Molecular Dynamics, Sunnyvale, CA). In some experiments, monoclonal antivinculin (1:500 dilution in blocking buffer) or antiserum 363 (1:500 dilution in blocking buffer) was used as the primary antibodies, and ${ }^{125} \mathrm{l}$-labeled protein $\mathrm{A}(0.15 \mu \mathrm{Ci} / \mathrm{ml}$; Amersham Corp.) was used as the secondary reagent.

\section{Immunoprecipitation and subcellular fractionation}

Immunoprecipitation was carried out by incubating detergent lysates with py20-agarose (ICN) at $4^{\circ} \mathrm{C}$ for $1 \mathrm{~h}$. The unbound fraction was collected by centrifugation, and, after washing in RIPA buffer, the bound fraction was obtained by boiling the py20-agarose beads for $3 \mathrm{~min}$ in SDS-sample buffer. For subcellular fractionation, cells were homogenized in hypotonic buffers ( $10 \mathrm{mM}$ Tris, $\mathrm{pH} 7.4,1 \mathrm{mM} \mathrm{MgCl}$ ) containing $2 \mathrm{mM}$ PMSF, $0.15 \mathrm{TIU} / \mathrm{ml}$ aprotinin, $1 \mu \mathrm{g} / \mathrm{ml}$ leupeptin, and $0.5 \mathrm{mM}$ vanadate. After removing nuclei by lowspeed centrifugation, cellular membrane and cytoplasmic fractions were separated by ultracentrifugation at 100000 $\times g$ for $1 \mathrm{~h}$. The pellet (membrane) fraction was dissolved in RIPA buffer to equal the volume of the cytosolic fraction.

\section{Acknowledgments}

This work was supported by grants from the USPHS, National Cancer Institute (PO1CA26712 and RO1CA17007), and by the Howard Hughes Medical Institute. We are grateful to John Glenney for a gift of antiphosphotyrosine antibodies, to Carla Grandori and John Peters for their critical reading of the text, and to Colleen Mazzeo Leslie for preparation of the manuscript.

Received: June 26, 1991.

Revised and accepted: August 9, 1991.

\section{References}

Buck, C.A., and Horwitz, A.F. (1987). Cell surface receptors for extracellular matrix molecules. Ann. Rev. Cell Biol. 3, 179-205.

Burridge, K., Fath, K., Kelly, T., Nuckolls, G., and Turner, C. (1988). Focal adhesions: transmembrane junctions between the extracellular matrix and the cytoskeleton. Annu. Rev. Cell Biol. 4, 487-525.

Dejana, E., Colella, S., Conforti, G., Abbadini, M., Gaboli, M., and Marchisio, P.C. (1988). Fibronectin and vitronectin regulate the organization of their respective Arg-Gly-Asp 
adhesion receptors in cultured human endothelial cells. J. Cell Biol. 107, 1215-1223.

Edelman, A.M., Blumenthal, D.K., and Krebs, E.G. (1987). Protein serine/threonine kinases. Annu. Rev. Biochem. 56, 567-613.

Ferrell, J.E., and Martin, G.S. (1989). Tyrosine-specific protein phosphorylation is regulated by glycoprotein Ilb-Illa in platelets. Proc. Natl. Acad. Sci. USA 86, 2234-2238.

Folkman, J., and Moscona, A. (1978). Role of cell shape in growth control. Nature 273, 345-349.

Glenney, J.R., Jr., Zokas, L., and Kamps, M.J. (1988). Monoclonal antibodies to phosphotyrosine. J. Immunol. Methods 109, 277-285.

Golden, A., Brugge, J.S., and Shattil, S.J. (1990). Role of platelet membrane glycoprotein IIb-llla in agonist-induced tyrosine phosphorylation of platelet proteins. J. Cell Biol. 111: 3117-3127.

Guan, J.-L., and Hynes, R.O. (1990). Lymphoid cells recognize an alternatively spliced segment of fibronectin via the integrin $\alpha_{4} \beta_{1}$. Cell 60, 51-63.

Hay, E.D. (ed.) (1985). Cell Biology of Extracellular Matrix, New York: Plenum

Hemler, M. (1990). VLA proteins in the integrin family: structure, functions, and their role on leukocytes. Annu. Rev. Immunol. 8, 365-400.

Hirst, R., Horwitz, A., Buck, C., and Rohrschneider, L. (1986). Phosphorylation of the fibronectin receptor complex in cells transformed by oncogenes that encode tyrosine kinases. Proc. Natl. Acad. Sci. USA 83, 6470-6474.

Horwitz, A., Duggan, K., Buck, C., Beckerle, M.C., and Burridge, $K$. (1986). Interaction of plasma membrane fibronectin receptor with talin- a transmembrane linkage. Nature 320 , 531-533.

Hunter, T. (1987). A thousand and one protein kinases. Cell $50,823-824$.

Hunter, T., and Cooper, J.A. (1985). Protein-tyrosine kinases. Annu. Rev. Biochem. 54, 897-930.

Hynes, R.O. (1987). Integrins: a family of cell surface receptors. Cell 48, 549-554.

Hynes, R.O. (1990). Fibronectins. New York: Springer-Verlag.

Kanner, S.B., Reynolds, A.B., Vines, R.R., and Parsons, J.T. (1990). Monoclonal antibodies to individual tyrosine-phosphorylated protein substrates of oncogene-encoded tyrosine kinases. Proc. Natl. Acad. Sci. USA 87, 3328-3332.

Laemmli, U.K. (1970). Cleavage of structural proteins during the assembly of the head of the bacteriophage T4. Nature $227,680-685$.

LeBaron, R.G., Esko, J.D., Woods, A., Johansson, S., and Hook, M. (1988). Adhesion of glycosaminoglycan-deficient chinese hamster ovary cell mutants to fibronectin substrate. J. Cell Biol. 106, 945-952.

Linder, M.E., and Burr, J.G. (1988). Nonmyristoylated p60vsrc fails to phosphorylate proteins of 115-120 kDa in chicken embryo fibroblasts. Proc. Natl. Acad. Sci. USA 85, 26082612.

Maher, P.A., arıd Pasquale, E.B. (1988). Tyrosine phosphorylated proteins in different tissues during chick embryo development. J. Cell Biol. 106, 1747-1755.
Maher, P.A., Pasquale, E.B., Wang, J.Y.J., and Singer, S.J. (1985). Phosphotyrosine-containing proteins are concentrated in focal adhesions and intercellular junctions in normal cells. Proc. Natl. Acad. Sci. USA 82, 6576-6580.

Marcantonio, E.E., Guan, J.-L., Trevithick, J.E., and Hynes, R.O. (1990). Mapping of the functional determinants of the integrin $\beta 1$ cytoplasmic domain by site-directed mutagenesis. Cell Regul. 1, 597-604.

Marcantonio, E.E., and Hynes, R.O. (1988). Antibodies to the conserved cytoplasmic domain of the integrin $\beta 1$ subunit react with proteins in vertebrates, invertebrates and fungi. J. Cell Biol. 106, 1765-1772.

Mosher, D.F. (ed.) (1989). Fibronectin. San Diego, CA: Academic Press.

Mould, A.P., Wheldon, L.A., Komoriya, A., Wayner, E.A., Yamada, K.M., and Humphries, M.J. (1990). Affinity chromatographic isolation of the melanoma adhesion receptor for the IIICS region of fibronectin and its identification as the integrin $\alpha_{4} \beta_{1}$. J. Biol. Chem. 265, 4020-4024.

Neff, N.T., Lowrey, C., Decker, C., Tovar, A., Damsky, C., Buck, C., and Horwitz, A.F. (1982). A monoclonal antibody detaches embryonic skeletal muscle from extracellular matrices. J. Cell Biol. 95, 654-666.

Otey, C.A., Pavalko, F.M., and Burridge, K. (1990). An interaction between $\alpha$-actinin and the $\beta 1$ integrin subunit in vitro. J. Cell Biol. 111, 721-729.

Pasquale, E.B., Maher, P.A., and Singer, S.J. (1988). Comparative study of the tyrosine phosphorylation of proteins in Swiss 3T3 fibroblasts stimulated by a variety of mitogenic agents. J. Cell. Physiol. 137, 146-156.

Rees-Jones, R.W., and Taylor, S.I. (1985). An endogenous substrate for the insulin receptor-associated tyrosine kinase. J. Biol. Chem. 260, 4461-4467.

Reynolds, A.B., Roesel, D.J., Kanner, S.B., and Parsons, J.T. (1989). Transformation-specific tyrosine phosphorylation of a novel cellular protein in chicken cells expressing oncogenic variants of the avian cellularsrc gene. Mol. Cell. Biol. 9, 629638.

Ruoslahti, E. (1988). Fibronectin and its receptors. Annu. Rev. Biochem. 57, 375-413.

Ruoslahti, E., and Pierschbacher, M.D. (1987). New perspectives in cell adhesion: RGD and integrin. Science 238, 491-497.

Ruoslahti, E., and Yamaguchi, Y. (1991). Proteoglycans as modulators of growth factor activities. Cell 64, 867-869.

Sadoul, J.L., Peyron, J-F., Ballotti, R., Debant, A., Fehlmann, $M$., and Van Obberghen, E. (1985). Identification of a cellular $110000-D a$ protein substrate for the insulin-receptor kinase. Biochem. J. 227, 887-892.

Sibley, D.R., Benovic, J.L., Caron, M.G., and Lefkowitz, R.J. (1987). Regulation of transmembrane signaling by receptor phosphorylation. Cell 48, 913-922.

Singer, I.I., Scott, S., Kawka, D.W., Kazazis, D.M., Gailit, J., and Ruoslahti, E. (1988). Cell surface distribution of fibronectin and vitronectin receptors depends on substrate composition and extracellular matrix accumulation. J. Cell Biol. 106, 2127-2182.

Solowska, J., Guan, J.-L., Marcantonio, E.E., Trevithick, J.E., Buck, C.A., and Hynes, R.O. (1989). Expression of normal and mutant avian integrin subunits in rodent cells. J. Cell Biol. 109, 853-861. 
Springer, T.A. (1990). Adhesion receptors of the immune system. Nature 346, 425-434.

Tamkun, J.W., DeSimone, D.W., Fonda, D., Patel, R.S., Buck, C., Horwitz, A.F., and Hynes, R.O. (1986). Structure of integrin, a glycoprotein involved in the transmembrane linkage between fibronectin and actin. Cell 42, 271-282.

Tapley, P., Horwitz, A.F., Buck, C.A., Burridge, K., Duggan, K., Hirst, R., and Rohrschneider, L. (1989). Analysis of the avian fibronectin receptor (integrin) as direct substrate for pp6 $6^{\mathrm{v}-\text { src }}$. Oncogene 4, 325-333.

Towbin, H., Staehlin, T., and Gordon, J. (1979). Electrophoretic transfer of protein from polyacrylamide gels to nitrocellulose sheets: procedure and some applications. Proc. Natl. Acad. Sci. 76, 4350-4354.

Tucker, R.W., Butterfield, C.E., and Folkman, J. (1981). Interaction of serum and cell spreading affects the growth of neoplastic and non-neoplastic fibroblasts. J. Supramol. Struct. Cell. Biochem. 15, 29-40.

Ullrich, A., and Schlessinger, J. (1990). Signal transduction by receptors with tyrosine kinase activity. Cell 61, 203-212.

Veillette, A., Bookman, M.A., Horak, E.M., and Bolen, J.B. (1988). The CD4 and CD8 T cell surface antigens are associated with the internal membrane tyrosine kinase $p 56^{\text {lck. }}$. Cell 55, 301-308.
Wayner, E.A., Garcia-Pardo, A., Humphries, M.J., McDonald, J.A., and Carter, W.G. (1989). Identification and characterization of the lymphocyte adhesion receptor for an alternative cell attachment domain (CS-1) in plasma fibronectin. J. Cell Biol. 109, 1321-1330.

Williams, L.T. (1989). Signal transduction by the plateletderived growth factor receptor. Science 243, 1564-1570.

Wittelsberger, S.C., Kleene, K., and Penman, S. (1981). Progressive loss of shape-responsive metabolic controls in cells with increasingly transformed phenotype. Cell 24, 859-866.

Woods, A., Johansson, S., and Hook, M. (1988). Fibronectin fibril formation involves cell interactions with two fibronectin domains. Exp. Cell Res. 177, 272-283.

Yamanashi, Y., Kakiuchi, T., Mizuguchi, J., Yamamoto, T., and Toyoshima, K. (1991). Association of B cell antigen receptor with protein tyrosine kinase Lyn. Science 251, 192194.

Yarden, Y., and Ullrich, A. (1988). Growth factor receptor tyrosine kinases. Annu. Rev. Biochem. 57, 443-478.

Yayon, A., Klagsbrun, M., Esko, J.D., Leder, P., and Ornitz, D.M. (1991). Cell surface, heparin-like molecules are required for binding of basic fibroblast growth factor to its high affinity receptor. Cell 64, 841-848. 